\title{
Zinc-Based Semiconductors/Polymer Thin Films Junction for Photovoltaic Application
}

\author{
Souad Al-bat'hi, K. A. Buhari, and M. I. Latiff \\ Department of Manufacturing and Materials Engineering, Faculty of Engineering, International Islamic University Malaysia, \\ Jalan Gombak, 53100 Kuala Lumpur, Malaysia \\ Correspondence should be addressed to Souad Al-bat'hi, su3ad@iium.edu.my
}

Received 16 August 2011; Accepted 21 December 2011

Academic Editor: Bhushan Sopori

Copyright ( $\odot 2012$ Souad Al-bat'hi et al. This is an open access article distributed under the Creative Commons Attribution License, which permits unrestricted use, distribution, and reproduction in any medium, provided the original work is properly cited.

Thin films of $\mathrm{ZnO}$ and $\mathrm{ZnTe}$ semiconductors were deposited on ITO conducting glass substrates by sputtering and electrodeposition techniques, respectively. On the other hand, thin films of ion conducting solid polymer electrolyte were prepared by solution cast technique. The polymer is a blend of $50 \mathrm{wt} \%$ polyethylene oxide and $50 \mathrm{wt} \%$ chitosan. To provide redox couple $\left(\mathrm{I}^{-} / \mathrm{I}^{3-}\right)$, the polymer was complexed with ammonium iodide $\mathrm{NH}_{4} \mathrm{I}$ with addition of few crystals of iodine $\mathrm{I}_{2}$. Ammonium iodide $\mathrm{NH}_{4} \mathrm{I}$ was added to the solution in different amounts ( $\mathrm{wt} \%$ ) weight ratios to supply the charge carriers for the polymer electrolytes. The highest ionic conductivity of the polymer electrolyte was $1.18 \times 10^{-5} \mathrm{~S} \mathrm{~cm}^{-1}$ at room temperature. Structural and optical properties of the semiconductor thin films were characterized by X-ray diffractometer and UV-Vis spectrophotometer. The XRD shows crystalline structures for both $\mathrm{ZnO}$ and $\mathrm{ZnTe}$ thin films. The UV-Vis shows direct energy gaps $\mathrm{E}_{\mathrm{ZnO}}$ of $3.1 \mathrm{eV}$ and $\mathrm{E}_{\mathrm{ZnTe}}$ of $2.2 \mathrm{eV}$. The polymer film was sandwiched between the $\mathrm{ZnO}$ and $\mathrm{ZnTe}$ semiconductors to form ITO/ZnO/polymer/ZnTe/ITO double-junction photovoltaic cell, and the photovoltaic properties were studied. The highest open-circuit voltage $V_{\mathrm{oc}}$, short-circuit current density $J_{\mathrm{sc}}$, and fill factor FF of the fabricated cells are $0.5 \mathrm{~V}, 55 \mu \mathrm{Acm}^{-2}$, and $27 \%$, respectively.

\section{Introduction}

The search for clean energy as an alternative to conventional energy sources is rapidly increasing in the recent past. Photovoltaic cells can be a promising candidate. Silicon has been the material of choice for photovoltaic designers because it is inexpensive and relatively well understood-and, of course, because it has properties that make it appropriate for photovoltaic applications $[1,2]$. Recent advances in photovoltaic technology, however, have made other materials in combination attractive for the design of solar cells. Designers layer semiconductor materials with differing bandgap energies to result in higher conversion efficiencies. Although silicon can be used as one of these layers [3], alloys combining Group II elements with Group VI elements are enticing choices because of the wide range of bandgap energies they offer the designers [4]. The photovoltaic designer must maximize power by optimizing the tradeoffs between current and voltage. To maximize current, it is desirable to capture as many photons from the spectrum of solar radiation as possible. A small bandgap may then be selected so that even photons with lower radiation energies can excite electrons into the conduction band. However, the small bandgap results in a lower photovoltage. Additionally, the photons with higher energies will have much of their energy wasted as heat, instead of conversion into electrical energy. Alternatively, the designer can choose a higher bandgap, but then will not capture any photon energy less than that bandgap, resulting in a lower photocurrent and, in turn, reducing the output current of the device. Multijunction cells use a combination of semiconductor materials to more efficiently capture a larger range of photon energies. They do so without sacrificing photovoltage or creating losses of heat to the degree of single-junction cells.

Multiple layer solar cells consist of semiconductors with decreasing bandgaps. The top layers are designed to absorb higher-energy photons while transmitting lower-energy photons that are absorbed by lower layers of the cell [5].

Decades of research on single-junction thin film solar cells led to an efficiency of $19.2 \%$ [6]. Higher efficiencies 
could be achieved by using stacked (multijunction)/tandem solar cell structures [7].

Employing wide and small bandgap semiconductors in a tandem solar cell reduces the energy losses inherent to singlejunction cells. The wide bandgap subcell lowers the thermalization losses associated with absorption of high-energy photons in a small bandgap cell, and on the other hand the small bandgap subcell absorbs the low-energy photons for which a wide bandgap cell is not sensitive. Hence in a tandem solar cell the photon energy can be better preserved. Recently semiconducting organic molecules and polymers are being considered for tandem solar cells, resulting in power conversion efficiencies over 5\% [8]. Multijunction solar cells have attracted many investigators in recent years. The last 2 decades have seen large improvements in III-V compound multijunction (MJ) solar cells. InGaP/InGaAs/Ge monolithic cascade 3-junction cells with newly recorded efficiency of $31.7 \%$ at AM 1.5 (1-sun) were achieved on Ge substrates [9]. III-V compound multijunction (MJ)/(tandem) solar cells have the potential for achieving high conversion efficiencies of over $50 \%$ and are promising for space and terrestrial applications [10]. Tandem junctions consisting of an amorphous silicon (a-Si:H) top cell and a microcrystalline silicon ( $\mu \mathrm{c}-\mathrm{Si}: \mathrm{H})$ bottom cell are of particular interest since by this concept stable solar energy conversion efficiencies of cells and modules well above $10 \%$ have been achieved [11].

This paper describes our recent progress in a zinc-based PV research. Alloys of Group II and Group VI elements as well as other related compounds that lend themselves well to the design of double-junction cells have been employed. Zinc oxide $(\mathrm{ZnO})$ thin film is one of the typical transparent conducting oxides with a large bandgap of $3.36 \mathrm{eV}$ suitable to the application for such hybrid photovoltaic devices [12]. The other semiconductor material used is zinc telluride ( $\mathrm{ZnTe})$ thin film. As it is a potentially low-cost semiconductor for switching devices and multijunction solar cells with a bandgap $2.26 \mathrm{eV}$ [13]. Results on the performance of ITO/ZnO/PEO/ZnTe/ITO double-junction photovoltaic cells have been reported.

\section{Experimental}

2.1. Preparation of Semiconductor Thin Films. $\mathrm{ZnO}$ thin films were deposited on ITO conducting glass substrates, by radio frequency (rf) magnetron sputtering technique (MUE-ECO, ULVAC, Inc.) by using $5.06-\mathrm{cm}$-diameter $\mathrm{ZnO}$ target with 99.99\% purity. The distance from the target to the substrate was $9.5 \mathrm{~cm}$ and the base pressure was $1 \times 10^{-4} \mathrm{~Pa}[14,15]$ whereas samples of ZnTe were prepared by electrodeposition technique [16]. The general approach of experimental and characterization details were described in an earlier work [17] and will not be repeated here. However, if excess of elemental chalcogenide is unavoidable in the $\mathrm{ZnTe}$ films, heat treatment allows its elimination.

2.2. X-Ray Diffraction. Structure and crystallography study of deposited $\mathrm{ZnTe}$ and $\mathrm{ZnO}$ thin films were examined by Xray diffractometer (Shimadzu 6000), with operating voltage and current of $40 \mathrm{kV}$ and $30 \mathrm{~mA}$, respectively. The X-ray wavelength is $1.54 \AA$ that proved the crystalline phase formation of cubic $\mathrm{ZnTe}$ and hexagonal wurtzite $\mathrm{ZnO}$ structures.

2.3. UV-Vis Characterization. For the determination of the energy gap of $\mathrm{ZnTe}$ and $\mathrm{ZnO}$ samples, the best method is to study the absorption edge through the measurement of the absorption spectra by using UV-Vis spectrophotometer (Lambda 35) with scan speed of $240 \mathrm{~nm} / \mathrm{min}$ that confirms energy bandgap of $\sim 2.3 \mathrm{eV}$ and $3.36 \mathrm{eV}$, respectively.

2.4. Preparation of Electrolyte. The electrolyte films were prepared by the solution cast technique. $0.25 \mathrm{~g}$ of PEO, polyethylene oxide (Aldrich), and $0.25 \mathrm{~g}$ chitosan (FLUKA) were dissolved in $1 \%$ acetic acid solution. Differing amounts of ammonium iodide $\left(\mathrm{NH}_{4} \mathrm{I}\right)$, according to the weight percentage ratio required, were added to the different solutions containing the same amount of PEO and chitosan (Table 1). The solutions were continuously stirred until complete dissolution of the salt. To get the redox couple, $\mathrm{I}^{-} / \mathrm{I}^{3-}$ some iodine $\left(\mathrm{I}_{2}\right)$ crystals were added to each of the solutions containing different amounts of $\mathrm{NH}_{4} \mathrm{I}$ and mixed thoroughly. The solutions were then cast in different Petri dishes and left to dry to form films.

2.5. Impedance Measurements. The nearly dry films were removed from the Petri dishes, cut to the required size, and the impedance were measured using the HIOKI 3531-01 LCR $\mathrm{Hi}$-Tester. Measurements were carried out over the frequency range from $50 \mathrm{~Hz}$ to $1 \mathrm{MHz}$. The conductivity $\sigma$ of the electrolyte films were calculated from the following equation:

$$
\sigma=\frac{t}{R_{b} A}
$$

where $t$ is thickness of the polymer film and $A$ is the electrolyte-electrode contact area and $R_{b}$ is the bulk resistance. The bulk resistance value $\left(R_{b}\right)$ was obtained from the plot (Figure 1) of negative imaginary impedance versus real impedance.

2.6. Device Assembly. Photovoltaic double-junction cells were constructed and assembled using an $\mathrm{ITO} / \mathrm{ZnO}$ window electrode and ITO/ZnTe counter electrode. The polymer electrolyte film with the highest room temperature conductivity was sandwiched between the two electrodes as shown in Figure 2. The photovoltaic properties of cells configuration ITO/ZnO/Polymer/ZnTe/ITO were studied. Current densityvoltage $(J-V)$ characteristics for the determination of open circuit voltage, $V_{\mathrm{oc}}$ and short-circuit current density; $J_{\mathrm{sc}}$ was carried out under dark and illuminated conditions. The effective area of the cell exposed to the light was $0.07 \mathrm{~cm}^{2}$. The fill factor (FF) can be calculated from the following equation:

$$
\mathrm{FF}=\frac{J_{\max } V_{\max }}{J_{\mathrm{sc}} V_{\mathrm{oc}}}
$$

$J_{\mathrm{sc}}$ is the short-circuit current density $\left(\mu \mathrm{Acm}^{-2}\right), V_{\mathrm{oc}}$ is the open-circuit voltage $(\mathrm{mV})$, and $J_{\max }\left(\mu \mathrm{Acm}^{-2}\right)$ and $V_{\max }$ $(\mathrm{mV})$ are the maximum current density and maximum 


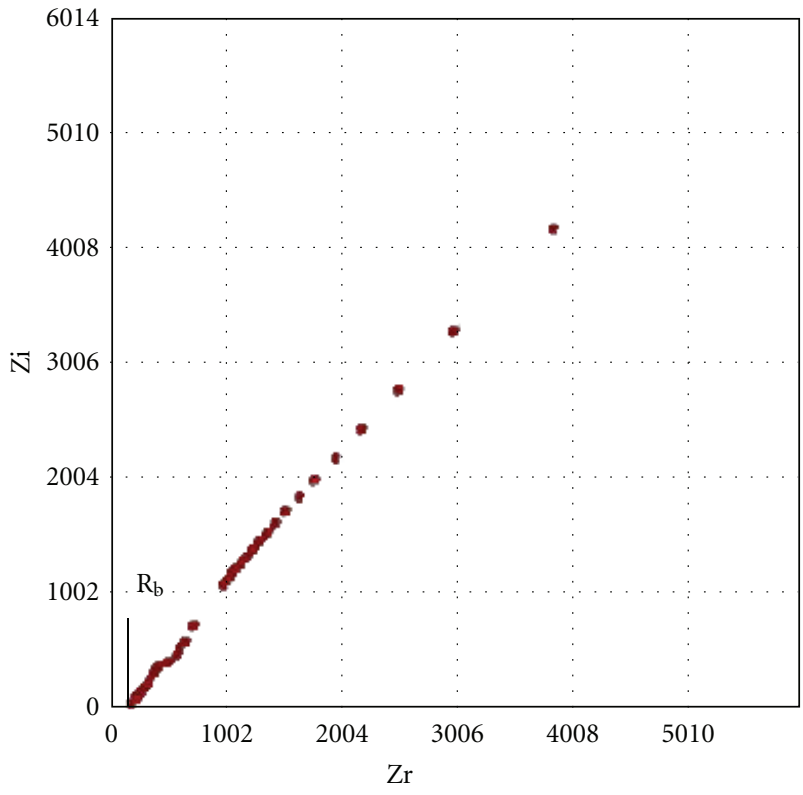

Figure 1: The Cole-Cole plot showing bulk resistance $R_{b}$ of sample containing $45 \%$ ammonium iodide.

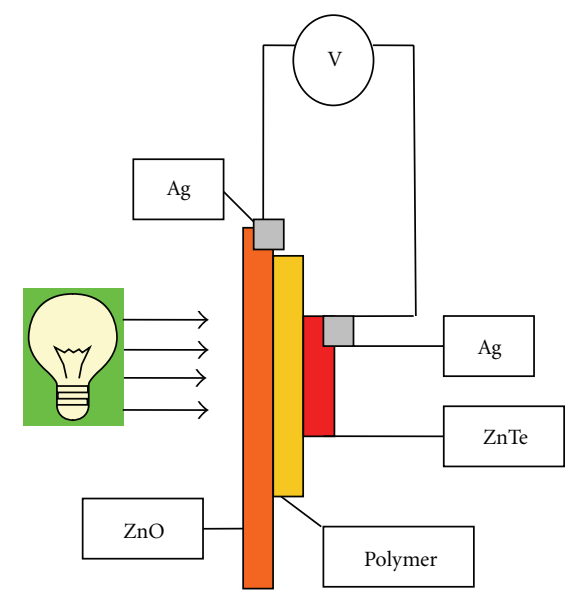

Figure 2: ZnO/polymer/ZnTe junction.

voltage in the $J-V$ curve, respectively, at the point of the maximum power output.

In this work a neon lamp was used for photoillumination. Alnama et al. [18] observed optogalvanic (OG) transitions corresponding to near-UV region between 380 and $420 \mathrm{~nm}$. The OG technique is a powerful spectroscopic tool that complements absorption spectroscopy. Zhu et al. [19] have reported 351 OG transitions in neon between 337 and $598 \mathrm{~nm}$, and 223 of these OG transitions are associated with neon transition. Reddy and Venkateswarlu [20] recorded about 300 transitions in the OG spectrum of neon in the visible wavelength region, $410-670 \mathrm{~nm}$. Thakur and Narayanan [21] observed two photon transitions from the metastable $3 \mathrm{~s}$ state to higher ns and nd states of neon between 500 and $548 \mathrm{~nm}$. These results show that the neon spectrum extends from the UV region and covers the visible range as well. Since the energy gap of $\mathrm{ZnO}$ and $\mathrm{ZnTe}$ films are $\sim 3.3 \mathrm{eV}$
TABLE 1: The electrolyte, composition and its conductivity at room temperature.

\begin{tabular}{lcccc}
\hline $\begin{array}{l}\text { Chitosan } \\
(\mathrm{g})\end{array}$ & $\begin{array}{c}\text { PEO } \\
(\mathrm{g})\end{array}$ & Wt. \% & $(\mathrm{g})$ & $\mathrm{NH}_{4} \mathrm{I}$ \\
\hline 0.25 & 0.25 & 0 & 0.000 & $(5.17 \pm 1.7) \times 10^{-10}$ \\
0.25 & 0.25 & 5 & 0.026 & $(1.59 \pm 3.5) \times 10^{-10}$ \\
0.25 & 0.25 & 10 & 0.055 & $(2.35 \pm 0.9) \times 10^{-10}$ \\
0.25 & 0.25 & 15 & 0.088 & $(8.52 \pm 2.4) \times 10^{-9}$ \\
0.25 & 0.25 & 20 & 0.125 & $(1.84 \pm 0.5) \times 10^{-8}$ \\
0.25 & 0.25 & 25 & 0.166 & $(1.84 \pm 0.6) \times 10^{-8}$ \\
0.25 & 0.25 & 30 & 0.214 & $(9.21 \pm 2.6) \times 10^{-8}$ \\
0.25 & 0.25 & 35 & 0.269 & $(2.25 \pm 1.3) \times 10^{-7}$ \\
0.25 & 0.25 & 40 & 0.333 & $(9.5 \pm 1.6) \times 10^{-7}$ \\
0.25 & 0.25 & 45 & 0.409 & $(1.18 \pm 0.7) \times 10^{-5 *}$ \\
0.25 & 0.25 & 50 & 0.500 & $(9.83 \pm 5.7) \times 10^{-6}$ \\
\hline
\end{tabular}

${ }^{*}$ : referring to the highest conductivity at room temperature.

and $2.2 \mathrm{eV}$, respectively, corresponding to a wavelength of $376 \mathrm{~nm}$ to $565 \mathrm{~nm}$, the neon lamp can therefore be used to illuminate the fabricated cells. The wavelength above $565 \mathrm{~nm}$ corresponding to the energy gap of ZnTe will be transmitted and will not be absorbed by the electrons in the semiconductors. The photons with energy greater than the energy gap can produce electron-hole pairs but the excess energy can be lost as heat.

\section{Results and Discussion}

3.1. Electrolyte Conductivity. The different compositions of the electrolyte prepared in this study with their room temperature conductivity are given in Table 1 that shows the highest conducting sample, prepared by using $0.25 \mathrm{~g}$ PEO, $0.25 \mathrm{~g}$ chitosan, and $0.409 \mathrm{~g} \mathrm{NH}_{4} \mathrm{I}$. Although the conductivity is not satisfactorily high enough, this sample was used to make the semiconductor/polymer/semiconductor doublejunction. Figure 1 shows Cole-Cole plot for the highest conducting sample at room temperature. The initial increase in conductivity is attributed to an increase in the number of mobile ions. However, the conductivity is then decreased due to the formation of neutral ion pairs, as a result of ion association. The intercept of the plot with the real impedance axis represents the electrolyte bulk resistance $R_{b}$. It is observed that the value of $R_{b}$ is decreasing for different compositions of the electrolyte prepared at room temperature, which lead to higher ionic conductivity, based on (1) in Section 2.5.

3.2. X-Ray Diffractogram. Figure 3 shows XRD pattern for $\mathrm{ZnO}$ thin film prepared at room temperature. The diffractogram exhibits peaks at $2 \theta=30.5^{\circ}$ and $34.7^{\circ}$. $\mathrm{ZnO}$ peaks are characteristic of the hexagonal form [22].

3.3. UV-Vis Spectrophotometry. To study the absorption edge through the measurement of the absorption spectra, we need to grow the $\mathrm{ZnO}$ samples onto an optically transparent 


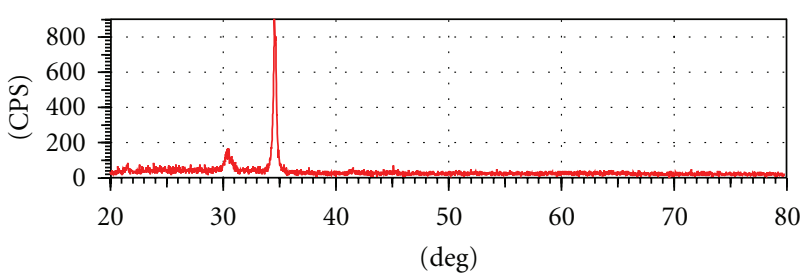

Figure 3: X-ray diffraction spectra of as-deposited $\mathrm{ZnO}$ films obtained at room temperature.

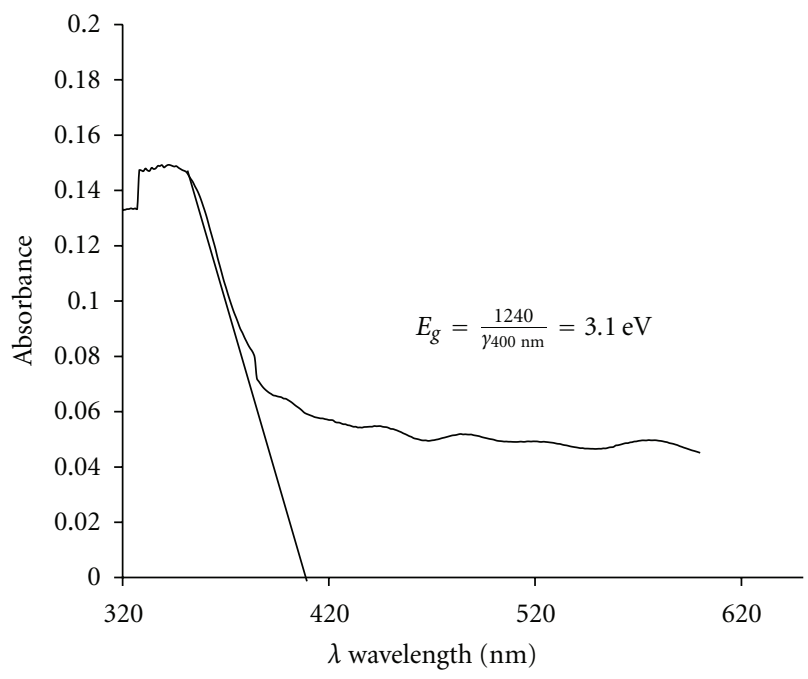

FIgURE 4: The absorption spectrum of $\mathrm{ZnO}$ thin film.

substrate, in the region of our interest. The best candidate is ITO coated glass, which is transparent in a spectral region that includes the visible wavelengths and extended to $320 \mathrm{~nm}$ in the ultraviolet. The energy gap value of the $\mathrm{ZnO}$ on ITO/glass is less than the expected room temperature energy gap reported for $\mathrm{ZnO}\left(E_{g}=3.4-3.3 \mathrm{eV}\right)[23,24]$.

Figure 4 shows the result of the optical absorption spectrum of $\mathrm{ZnO}$ thin film sputtered on ITO/glass substrate. The extrapolation intersects with the wavelength axis at $\lambda$ $=400 \mathrm{~nm}$ presenting the corresponding energy gap $\left(E_{g}=\right.$ $3.1 \mathrm{eV}$.) of $\mathrm{ZnO}$ thin film on ITO/glass at room temperature not far from the 3.4-3.3 eV reported by [23]. This result shows that the prepared film is suitable for use for photovoltaic cell applications as window materials.

3.4. Device Fabrication and Characterization. For device fabrication, the polymer electrolyte film with the highest room temperature conductivity was sandwiched between the $\mathrm{ZnO}$ and $\mathrm{ZnTe}$ semiconductors as shown in Figure 2.

The highest short-circuit current density; $J_{s c}$, opencircuit voltage $V_{\mathrm{oc}}$ and the fill factor $\mathrm{FF}$ obtained from the cell with configuration ITO/ZnO/Polymer/ZnTe/ITO are $55 \mu \mathrm{A} \mathrm{cm}^{-2}, 0.5 \mathrm{~V}$, and $27 \%$ respectively. The $J-V$ characteristics of the $\mathrm{ZnO} /$ polymer/ZnTe cells in the dark and under white light are shown in Figure 5. In the dark, the system operates as a diode, since it shows a diode-like characteristic and Schottky-type behavior. Under illumination the system operates as a solar cell.

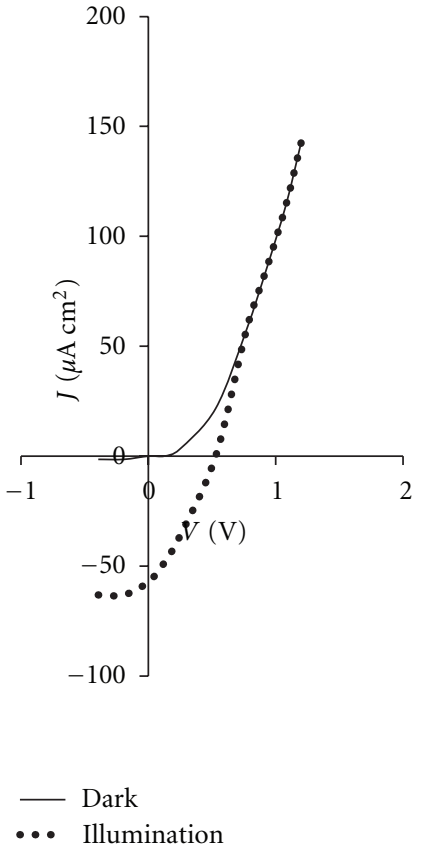

Figure 5: $J-V$ Characteristic of $\mathrm{ZnO} /$ polymer/ZnTe in the dark and under illumination.

Excess iodine in the polymer electrolyte initiates $\mathrm{I}^{-} / \mathrm{I}^{3-}$ redox couple. During preparation of the electrolyte film, the $\mathrm{NH}_{4} \mathrm{I}$ salt dissociates into $\mathrm{NH}_{4}^{+}$and $\mathrm{I}^{-}$.

Upon illumination, electrons in the valence band of $\mathrm{ZnO}$ semiconductor are exited into the conduction band due to absorption of photons energy. These electrons will flow to the counter electrode ZnTe through the external circuit. The less energetic photons that are not absorbed in the $\mathrm{ZnO}$ layer will penetrate the polymer electrolyte to the counter electrode ZnTe where it can be absorbed and free electrons will be released. Within the electrolyte a triiodide ion formed from interaction between a monoiodide ion and an iodine molecule:

$$
\mathrm{I}^{-}+\mathrm{I}_{2} \longrightarrow \mathrm{I}^{3-} .
$$

At the interface between electrolyte and $\mathrm{ZnTe}$ counterelectrode, triiodide ion is reduced by an electron to a monoiodine ion and an iodine atom:

$$
\mathrm{I}^{3-}+\mathrm{e}^{-} \longrightarrow 2 \mathrm{I}^{-}+\frac{1}{2} \mathrm{I}_{2}
$$

At the interface between electrolyte and $\mathrm{ZnO}$ electrode, the monoiodine ion releases the electron back to $\mathrm{ZnO}$ semiconductor by oxidation as shown below and the cycle continues:

$$
\mathrm{I}^{-} \longrightarrow \frac{1}{2} \mathrm{I}_{2}+\mathrm{e}^{-}
$$

\section{Conclusions}

Double-junction photovoltaic cells of structure ITO/ZnO/ PEO-chitosan/ZnTe/ITO were fabricated by using different 
techniques. Sputtering for $\mathrm{ZnO}$ fabrication, electrodeposition for ZnTe, and solution cast technique for solid-state polymer electrolyte. Structural and optical characterization of $\mathrm{ZnO}$ and $\mathrm{ZnTe}$ exhibits hexagonal and cubic structures, respectively, and energy gap of 3.1 and $2.2 \mathrm{eV}$, respectively. Electrical characterization of the polymer electrolyte has shown highest conductivity of $1.18 \times 10^{-5} \mathrm{~S} \mathrm{~cm}^{-1}$. Device performance has been measured in the dark and under illumination. We have shown that PEO-chitosan blend can host the redox $\mathrm{I}^{-} / \mathrm{I}^{3-}$ couple for the operation of double-junction photovoltaic cells. The performance of the semiconductor/polymer electrolyte/semiconductor double-junction solar cell can still be improved by improving the electrolyte conductivity. The highest short-circuit current density; $J_{s c}$, opencircuit voltage $V_{\mathrm{oc}}$ and the fill factor FF obtained from the cell with configuration ITO/ZnO/polymer/ZnTe/ITO are $55 \mu \mathrm{A} \mathrm{cm}^{-2}, 0.5 \mathrm{~V}$ and $27 \%$, respectively. The low output current can be attributed to the low conductivity of the electrolyte.

\section{References}

[1] V. Badescu, "Simple optimization procedure for silicon-based solar cell interconnection in a series-parallel PV module," Energy Conversion and Management, vol. 47, no. 9-10, pp. 1146$1158,2006$.

[2] R. K. Ahrenkiel, "Recombination processes and lifetime measurements in silicon photovoltaics," Solar Energy Materials and Solar Cells, vol. 76, no. 3, pp. 243-256, 2003.

[3] X. Deng, "Study of triple-junction amorphous silicon alloy solar cells," AIP Conference Proceedings, vol. 462, pp. 297-302, 1998.

[4] T. Skotheim, "A tandem photovoltaic cell using a thin-film polymer electrolyte," Applied Physics Letters, vol. 38, no. 9, pp. 712-714, 1981.

[5] W. A. Daoud and M. L. Turner, "Effect of interfacial properties and film thickness on device performance of bilayer $\mathrm{TiO}_{2}$ poly (1,4-phenylenevinylene) solar cells prepared by spin coating," Reactive and Functional Polymers, vol. 66, no. 1, pp. 1320, 2006.

[6] K. Ramanathan, M. A. Contreras, C. L. Perkins et al., "Properties of $19.2 \%$ efficiency $\mathrm{ZnO} / \mathrm{CdS} / \mathrm{CuInGaSe} \mathrm{C}_{2}$ thin-film solar cells," Progress in Photovoltaics: Research and Applications, vol. 11, no. 4, pp. 225-230, 2003.

[7] H. S. Ullal, K. Zweibel, and B. Von Roedern, "Polycrystalline thin film photovoltaics: research, development, and technologies," in Proceedings of the 29th IEEE Photovoltaic Specialists Conference, pp. 472-477, New Orleans, La, USA, May 2002.

[8] T. Ameri, G. Dennler, C. Lungenschmied, and C. J. Brabec, "Organic tandem solar cells: a review," Energy \& Environmental Science, vol. 2, no. 4, pp. 347-363, 2009.

[9] M. Yamaguchi, "III-V compound multi-junction solar cells: present and future," Solar Energy Materials and Solar Cells, vol. 75, no. 1-2, pp. 261-269, 2003.

[10] M. Yamaguchi, T. Takamoto, and K. Araki, "Super high-efficiency multi-junction and concentrator solar cells," Solar Energy Materials and Solar Cells, vol. 90, no. 18-19, pp. 30683077, 2006.

[11] J. Meier and S. Dubail, in Proceedings of the 1st World Conference onPhotovoltaic Energy Conversion, p. 409, Vienna, Austria, 1994.
[12] M. S. White, D. C. Olson, S. E. Shaheen, N. Kopidakis, and D. S. Ginley, "Inverted bulk-heterojunction organic photovoltaic device using a solution-derived $\mathrm{ZnO}$ underlayer," Applied Physics Letters, vol. 89, no. 14, Article ID 143517, 2006.

[13] B. M. Basol and V. K. Kapur, "Preparation of ZnTe thin films using a simple two-stage process," Thin Solid Films, vol. 165, no. 1, pp. 237-241, 1988.

[14] S. J. Lim, S. Kwon, and H. Kim, "ZnO thin films prepared by atomic layer deposition and $\mathrm{rf}$ sputtering as an active layer for thin film transistor," Thin Solid Films, vol. 516, no. 7, pp. 15231528, 2008.

[15] H. S. Yoon, K. S. Lee, T. S. Lee et al., "Properties of fluorine doped $\mathrm{ZnO}$ thin films deposited by magnetron sputtering," Solar Energy Materials and Solar Cells, vol. 92, no. 11, pp. 1366-1372, 2008.

[16] M. Neumann-Spallart and C. Königstein, "Electrodeposition of zinc telluride," Thin Solid Films, vol. 265, no. 1-2, pp. 3339, 1995.

[17] S. A. Mohamad, W. J. Basirun, Z. A. Ibrahim, A. K. Arof, and M. Ebadi, "Structure and optical characterization of electrodeposited zinc selenide thin films," in Proceedings of the International Conference on Advances in Materials and Processing Technology (AMPT '09), Kuala Lumpur, Malaysia, October 2009.

[18] K. Alnama, J. H. Fillion, and D. Gauyacq, "Rydberg transitions in neon observed by optogalvanic effect in the 830-870 and 380-420 nm regions," Journal of Quantitative Spectroscopy and Radiative Transfer, vol. 105, no. 1, pp. 139-147, 2007.

[19] X. Zhu, A. H. Nur, and P. Misra, "Laser optogalvanic wavelength calibration with a commercial hollow cathode ironneon discharge lamp," Journal of Quantitative Spectroscopy and Radiative Transfer, vol. 52, no. 2, pp. 167-177, 1994.

[20] B. R. Reddy and P. Venkateswarlu, "Optogalvanic effect in neon hollow cathode discharge," Optics Communications, vol. 85, no. 5-6, pp. 491-499, 1991.

[21] S. N. Thakur and K. Narayanan, "Rydberg series in the visible two-photon optogalvanic spectrum of neon," Optics Communications, vol. 94, no. 1-3, pp. 59-65, 1992.

[22] S. Sanchez, C. Lucas, G. S. Picard, M. R. Bermejo, and Y. Castrillejo, "Molten salt route for ZnSe high-temperature electrosynthesis," Thin Solid Films, vol. 361, pp. 107-112, 2000.

[23] J. S. Tawale, K. K. Dey, R. Pasricha, K. N. Sood, and A. K. Srivastava, "Synthesis and characterization of $\mathrm{ZnO}$ tetrapods for optical and antibacterial applications," Thin Solid Films, vol. 519, no. 3, pp. 1244-1247, 2010.

[24] M. Purica, E. Budianu, E. Rusu, M. Danila, and R. Gavrila, "Optical and structural investigation of $\mathrm{ZnO}$ thin films prepared by chemical vapor deposition (CVD)," Thin Solid Films, vol. 403-404, pp. 485-488, 2002. 


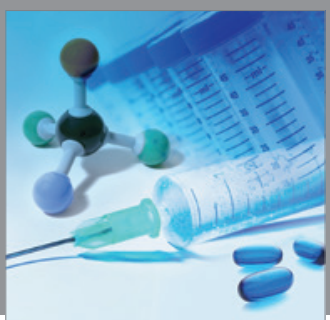

International Journal of

Medicinal Chemistry

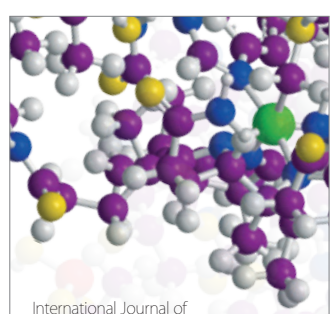

Carbohydrate Chemistry

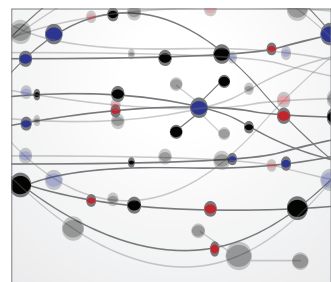

The Scientific World Journal
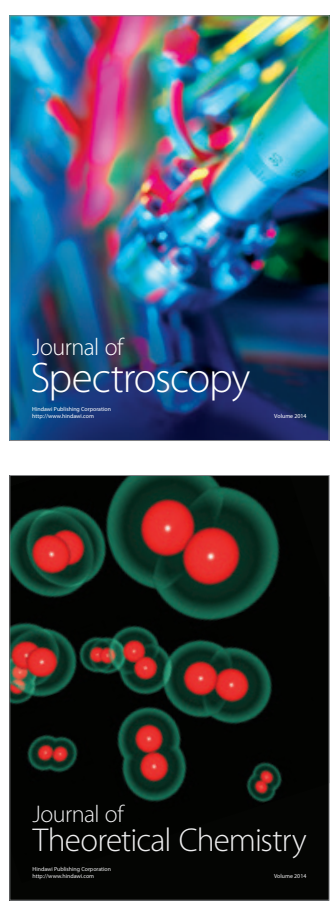
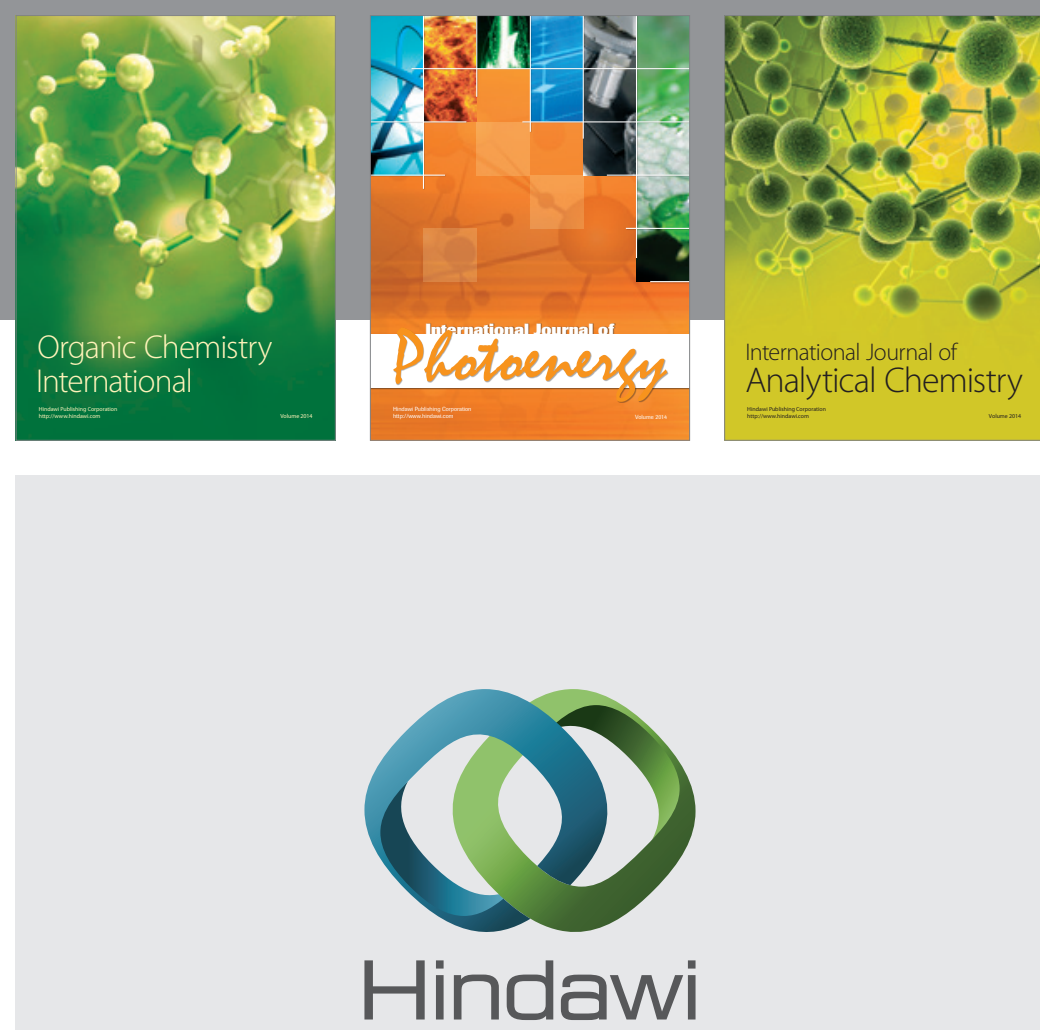

Submit your manuscripts at

http://www.hindawi.com
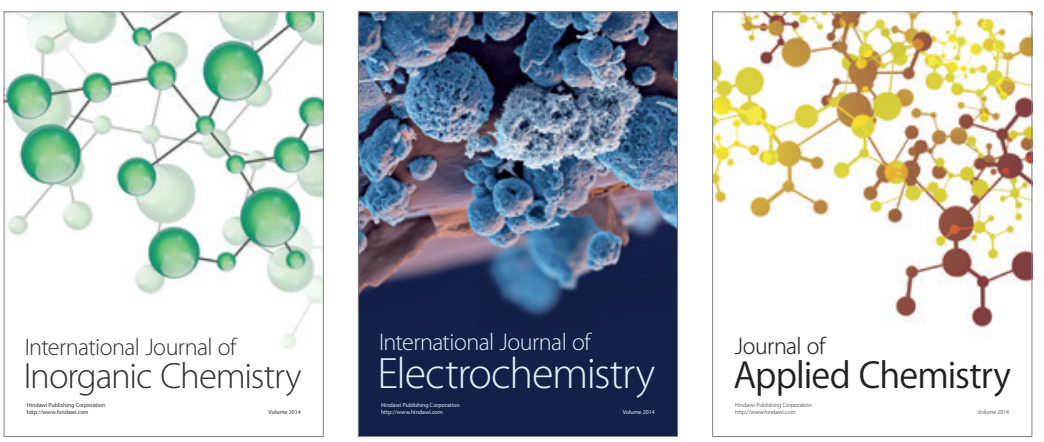

Journal of

Applied Chemistry
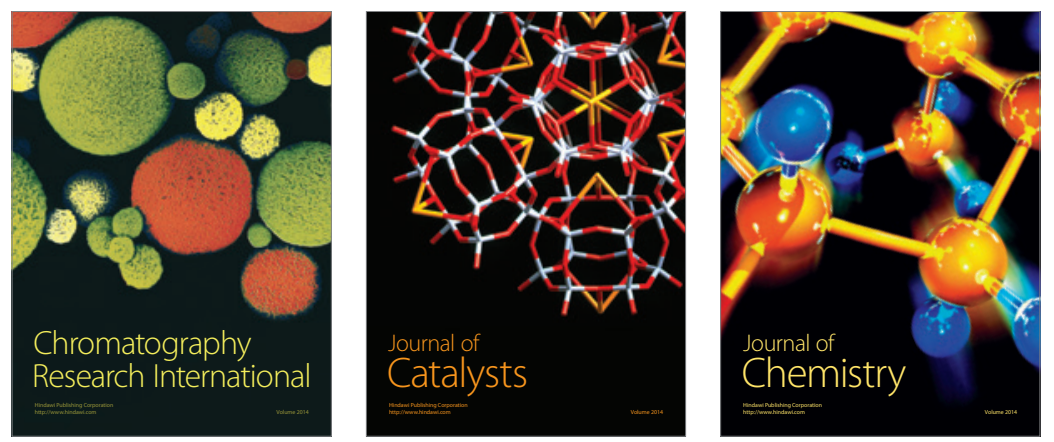
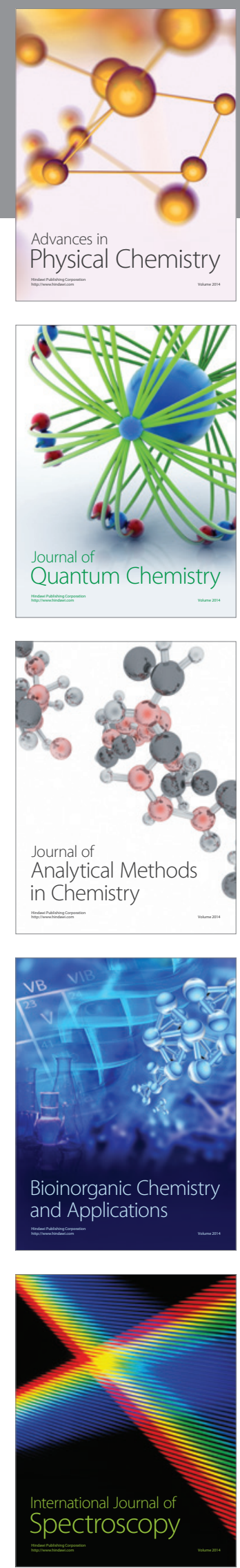